\title{
CHWALISZ, Claudia. The populist signal: why politics and democracy need to change. London: Rowman \& Littlefield, 2015.
}

\author{
Isabele B. Mitozo ${ }^{\dagger}$
}

Claudia Chwalisz é uma pesquisadora canadense, especialista em inovações democráticas e democracia deliberativa, que atua como consultora de pesquisa na agência Populus. É, ainda, associada ao Crick Centre for the Public Understanding of Politics, da Universidade de Sheffield, no Reino Unido. A autora tem voltado sua pesquisa, há alguns anos, para as relações que podem ser mantidas entre o desenvolvimento de novas práticas democráticas - especialmente aquelas em ambiente online - e o populismo, o que resultou em duas obras, dentre elas The Populist Signal.

O livro, lançado em 2015 - embora ainda pouco conhecido no Brasil -, traz uma abordagem original acerca do populismo contemporâneo, partindo do reconhecimento de que um sentimento de insatisfação ronda as instituições políticas desde o advento da democracia representativa e da constatação de que esse sentimento se acentua em determinados contextos. A pesquisa se desenvolve a partir de três questionamentos acerca de como evitar a expansão desse fenômeno: 1) Como engajar as pessoas novamente em um projeto político reflexivo? 2) É necessária uma descentralização do poder e novas formas de construção institucional? 3) Precisamos de uma democracia mais direta? (p. 10).

A fim de responder às referidas perguntas de pesquisa, a autora desenvolve um estudo empírico do caso britânico a respeito da percepção pública dos processos democráticos. Ademais, ela suscita outros países, a fim de exemplificar como a política tem passado por mudanças pelo mundo. Desse modo, o estudo não tem por foco condicionantes econômicos ou culturais gerais do populismo, mas, sim, como cidadãos e cidadãs "sentem que a política não funciona e como isso inflama o apoio a partidos e atores insurgentes"

A obra está dividida em três capítulos, que fazem um percurso desde a compreensão do populismo como processo aos conceitos e práticas de democracia deliberativa, especialmente a partir do desenvolvimento de modalidades de engajamento público por meio da plataforma online. O sistema democrático deliberativo consistiria em um modelo que aproximaria representantes e representados, servindo de "remédio" àquela "patologia política", como ela denomina o populismo (p. 8).

O primeiro capítulo discute características no comportamento dos indivíduos em relação ao campo político que podem conduzi-los ao apoio a movimentos populistas. A crescente (a)

\footnotetext{
† Doutoranda em Ciência Política na Universidade Federal do Paraná e Mestra em Comunicação pela Universidade Federal do Ceará. Pesquisadora associada ao Instituto Nacional de Ciência e Tecnologia em Democracia Digital (INCT-DD). E-mail: ibmitozo@gmail.com

1 Todas as traduções de trechos do livro aqui utilizados são de responsabilidade da autora da resenha.
}

Conexão Política, Teresina v. 6, n. 2, $123-126$, jul./dez. 2017 
desafeição pela política, marcada pela visão das elites desse campo como ameaças à soberania dos representados constituiria, segundo Chwalisz, o primeiro fator a contribuir para o desenvolvimento do apoio a pautas populistas.

O estudo do caso britânico aponta que, desde o surgimento do United Kingdom Independent Party (UKIP) ${ }^{2}$, em 1993, os níveis de desconfiança na política, que já eram altos entre eleitores de modo geral, ficam em torno de $26 \%$ mais altos entre aqueles que direcionaram seu voto ao referido partido populista. É interessante perceber, portanto, que o perfil dos cidadãos que tendem ao populismo é o mesmo em diferentes localidades apresentadas pela pesquisadora: homens mais velhos, trabalhadores "colarinho azul" e, majoritariamente, indivíduos sem formação universitária.

Esse fenômeno seria ainda mais inflamado (b) pelas mudanças nos valores e pelo choque geracional contrastados ao engessamento das pessoas mais antigas. Essas alterações nas dinâmicas cotidianas suscitariam a ideia do "outro", figura que se assenta nas minorias - como imigrantes negros e muçulmanos -, visto como perigoso à estabilidade social da comunidade dos "iguais".

Nesse contexto, os mais jovens não encontram identificação com a forma tradicionalmente hierárquica de fazer política. De acordo com o caso estudado, eles são "individualistas pragmáticos" e essa característica, combinada ao advento das tecnologias digitais, contribuiu para mudanças nas relações de poder, gerando motivações ao engajamento público. A maior exposição do campo político, principalmente de seus vícios e privilégios, leva os cidadãos a desafiarem essa esfera a reconfigurar as formas tradicionais de representação em que ela se sustenta.

Essa percepção conduz a argumentação de Chwalisz, no segundo capítulo, à defesa das inovações democráticas e à consequente formação do que ela nomeia "democracia de contato" como antídoto à alienação política. Nesse momento, é travado um diálogo com teorias democráticas, como a participativa (PATERMAN, 1970), a direta (BARBER, 2003/1984) e a deliberativa - desde a proposta de minipúblicos de Fishkin, no final dos anos 1980, à segunda fase dos estudos dessa vertente, consolidada no início dos anos 2000. Essa reflexão resulta em uma visão de que verdadeiras inovações democráticas são caracterizadas por três fatores: "deliberação, seleção aleatória e influência direta" (p. 34) nas questões políticas.

Desse modo, o desenvolvimento das práticas inovadoras se constitui como um desafio, pois elas devem contribuir para a otimização dos resultados do processo de decisão política. Os cidadãos e cidadãs precisam ser levados a sério, pois seu envolvimento em uma esfera de influência sobre os representantes traz ao centro de decisão o conhecimento da realidade comum, distante das elites que ocupam a posição de mandatários, o que a autora constata a partir da análise de algumas iniciativas de sucesso e de outras malsucedidas. Além disso, se o intuito é evitar ou reverter a alienação política, práticas como Assembleias de Cidadãos podem ser efetivas, uma vez que eleitores de partidos populistas se mostraram, de acordo com a pesquisa de Chwalisz, aqueles mais disponíveis a participar desse tipo de atividade, especialmente quando está envolvido um poder efetivo de decisão.

Não se pode deixar de notar um otimismo da pesquisadora ao propor sistemas de escolha

\footnotetext{
${ }_{2}$ Esse partido foi o maior apoiador e condutor de campanha a favor do voto pela saída do Reino Unido do bloco econômico europeu.
}

Conexão Política, Teresina v. 6, n. 2, $123-126$, jul./dez. 2017 
de representantes para as Câmaras Legislativas locais baseados na lógica do sorteio. Conforme a própria investigação constata a partir do survey aplicado, cidadãos e cidadãs apresentam receios a essa proposta. Esses atores estão mais interessados em ser ouvidos (have a say), mas não responsabilizados pela tomada de decisão em si. Esse resultado vai ao encontro do que afirmaram outros trabalhos, ao estudar o mesmo caso, como aquele de Fox (2009), que encontra uma certa acomodação pública, mesmo diante do escândalo de corrupção que atingia a Casa dos Comuns britânica naquele ano.

O terceiro capítulo apresenta o estudo de iniciativas - em níveis local, regional e nacional - desenvolvidas em Bélgica, Austrália, Canadá, Noruega, Holanda, Islândia e Irlanda. Segundo a autora, os projetos demonstram como as inovações democráticas podem aproximar os cidadãos do processo de tomada de decisão política, muitas vezes utilizando-se de mecanismos digitais. Aqui, persiste a defesa de que os cidadãos, quando selecionados aleatoriamente para constituir um corpo deliberativo, teriam vontade de defender melhor os interesses da sociedade.

Uma perspectiva interessante apresentada na obra é que a entrada do populismo em democracias pelo mundo ocorreu por meio do sistema eleitoral proporcional, pois, no caso Britânico, o sistema distrital majoritário evitou que o UKIP alcançasse, em vez de apenas uma, 80 cadeiras no parlamento em 2010. O partido conquistara quase 4 milhões de votos no país, o terceiro mais votado, tendo chegado em segundo lugar em mais de 100 disputas distritais naquelas eleições gerais. Esse sucesso é apontado pela pesquisadora como, ainda, efeito de "partido cartel", uma vez que os partidos do mainstream "têm usado os recursos do Estado para limitar a competição política e garantir a vitória eleitoral" (p. 7), mais que se preocupado em resolver ou mesmo abordar problemas estruturais reais, como o fator migratório na Europa. E os populistas possuem grande habilidade para conquistar "públicos desiludidos com soluções simples para problemas complexos" (p. 17).

Os resultados da pesquisa parecem servir a todo momento de alerta, sobretudo para os partidos de centro-esquerda, uma vez que a autora defende que "o populismo pode ser visto como um sinal corretivo para a democracia, se ele força políticos e partidos a renunciarem a sua compreensão de poder e explorarem formas inovadoras de dar genuinamente voz às pessoas nas decisões que as afetam" (p. 64-65). Os casos estudados mostram que, quando há oportunidades de apresentar e discutir demandas junto ao centro de decisão, os cidadãos mostram grande capacidade de julgar e compreender questões complexas.

Para concluir, Chwalisz afirma que não há fórmula única para o desenvolvimento de iniciativas, mas existe uma certeza: devem acontecer reformas profundas nos sistemas políticos a fim de que modelos deliberativos de práticas democráticas sejam estabelecidos como parte do processo de decisão política. Essas mudanças devem confrontar os atuais sistemas partidários, para que se abra espaço a uma construção coletiva das decisões como complemento à democracia representativa. Vale ressaltar que, embora otimista, a autora não deixa de considerar que essas inovações não seriam soluções instantâneas e, portanto, não reconstruiriam de imediato a confiança da esfera civil, anulando os efeitos das práticas populistas.

Em um contexto já desenhado pelo expressivo desempenho eleitoral de partidos populis-

Conexão Política, Teresina v. 6, n. 2, 123 -126, jul./dez. 2017 
tas nas eleições britânicas, mas ainda não marcado por Donald Trump (EUA) e pela campanha a favor do Brexit (UK), o livro se torna leitura obrigatória para quem se interessa pelo tema, por ter se constituído como um binóculo para o contexto político-eleitoral que se formaria um ano após o lançamento da obra.

\section{Referências adicionais}

BARBER, Benjamin. Strong democracy: participatory politics for a new age. Berkeley and Los Angeles: University of California Press, 2003.

FOX, Ruth. Engagement and participation: what the public want and how our politicians need to respond. Parliamentary affairs, v. 62, n. 4, p. 673-685, 2009.

PATEMAN, Carole. Participation and democratic theory. London: Cambridge University Press, 1970.

Conexão Política, Teresina v. 6, n. 2, $123-126$, jul./dez. 2017 